Rapid Reviews COVID-19

\title{
Reviews of "Disparities in COVID-19 Fatalities among Working Californians"
}

\section{Isobel Routledge' ${ }^{1}$ Yi Li $^{2}$}

${ }^{1}$ UCSF, ${ }^{2}$ University of Michigan

Published on: Dec 28, 2021

License: Creative Commons Attribution 4.0 International License (CC-BY 4.0). 
To read the original manuscript, click the link above.

Summary of Reviews: Cummings et al assessed occupation-specific COVID-19 mortality rates in California to find that manual labor and in-person service occupations experienced disproportionate COVID-19 mortality. While reviewers note potential underreporting and demographic ambiguities, they agree that the preprint does outline such limitations and ultimately sheds light on important health disparities.

Reviewer 1 (Isobel R... | प्म०

Reviewer 2 (Yi L...)

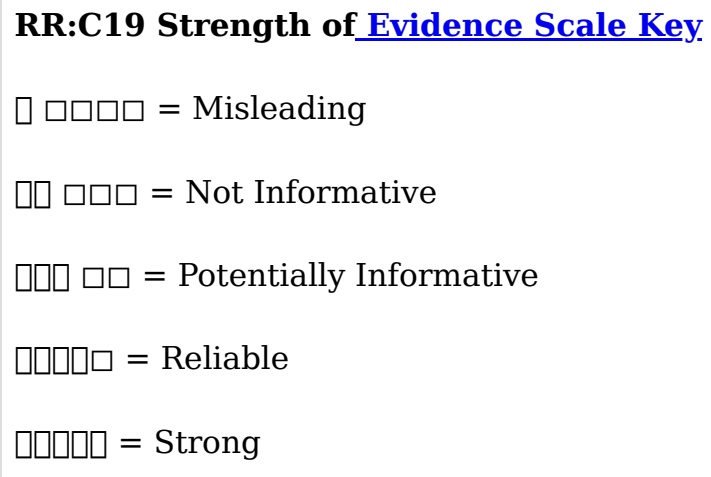

To read the reviews, click the links below. 